\section{PRACTICAL REMARKS ON LARYNGEAL DISEASE AS ILLUSTRATED BY THE LARYNGOSCOPE.}

By E. H. Sinveking, M.D.

[Read before the Harveian Society, November 20th, 1862.]

I TRUST, sir, that I do not lay myself open to the charge of presumptuousness in venturing to offer to you and the members of the Harveian Society some remarks on laryngeal disease, as illustrated by the laryngoscope. When, at the last meeting, you stated that there was a lacuna in the papers for this evening, I, perhaps somewhat rashly, volunteered to make some remarks on the subject; and I tender you my sincere apologies for the desultory manner in which $I$ am compelled to treat it. But I admit that I was urged to come forward as I have done by observing, in the course of numerous conversa. tions with my professional brethren, that the advantage offered by this new method of investigating an important class of diseases was not yet appreciated as I believe it merits. A very limited number of medical men have among ourselves familiarised themselves with its use, and the public press has brought but little evidence that it has yet been turned to much account. I think that the laryngoscope is just one of those aids to accurate medicine which ought, like the stethoscope, to be in the hands of every practitioner. It is so manifestly calculated to throw much light upon a class of diseases that have hitherto been but ill understood, that it ought to become common property; and it is with a view to bring forward a few facts that may indicate its value and convince you of the necessity of rescuing it from un. merited neglect, that I venture to bring before you the results of a comparatively limited experience, rather than with a feeling that I have anything novel or valuable to communicate.

Having, a good many years ago, felt the desirability of bringing the larynx within the range of vision, I my. self sought to obtain that object by the introduction of a mirror into the pharynx. I must, however, admit my complete failure, from the want of that ingenuity and perseverance which have enabled others to succeed. Although, however, what I have this evening to say is based upon the knowledge acquired through the welldirected efforts of $\mathrm{my}$ friend Professor Czermak of Prague, it is but just to the memory of one who was probably well known to and esteemed by many of us, the late Mr. Avery, to state that he invented an excellent laryngoscope, which, but for his premature death, would certainly have been made better known to the profession. His instrument shows that he thoroughly understood all the objects to be gained, and had overcome the main difficulties in achieving them. It combines all the essentials requisite for obtaining a view of the interior of the larynx, and possesses merits which have not yet been realised by more modern laryngoscopists. The apparatus of $\mathrm{Mr}$. Avery, however, laboured under certain defects which prevented its being very generally em. ployed, especially unless its value were demonstrated by the manipulative skill of its inventor. These defects would doubtless have been remedied, had he survived. If, in dealing with the history of laryngoscopy, the name of the English surgeon demands a prominent position, we must also bear in mind that England gave birth to the first essay in laryngoscopy, though it proceeded from the pen of a foreign artist. I allude to the very interest. ing researches of $M$. Garcia, which, under the title of "Observations on the Human Voice", were published in the seventh volume of the Proceedings of the Royal So- ciety, where this gentleman, the well-known brother $\Phi_{f}$ the famous Madame Malibran, made known a seriescaf excellently conceived and carefully executed observations on the movements of his vocal cords in vocalisation.

Whatever merit is due to the two gentlemen just named, the greatest praise is due to Dr. Czermak and other continental philosophers for having fairly render laryngoscopy a means for the detection and treatment disease. Dr. Czermak especially has popularised it showing its practical utility, and introducing his mirrors in England. He has simplified it so that comparative slight practice will enable any medical man to look inte the larynx and trachea; and he has thus removed the affections of these parts from the domain of dreamland, to which they have hitherto belonged. His work, ably translated by Dr. Gibb for the new Sydenham Societs, is in the hands of most of you; and I would specially re commend it to your attentive perusal, if you have no. already studied it. But I fear that, without the stimu lus which Dr. Czermak gave to laryngoscopy by his pef sonal visit to London during the past summer, the suba ject would scarcely have attracted even as much attention as it has. While he was here, he gave a series of $d \xi_{0}$ monstrations, and astonished many physicians and sus geons, not ill versed in their profession, by the remark able display of his own vocal organs which great practiog in auto-laryngosopy enabled him to make. At the same time, some of us took advantage of the instruction hes kindly imparted to overcome the A B C of laryngoscop manipulation. There is but little, indeed, to show this respect; but, as we all know, "c'est le premier pos qui coute". We are all of us liable to the false shame of disliking the first step in an unexplored region, and are very grateful to any one who will carry us over thes boundary, even though the barriers seem no barriens all after they have been once passed.

And let me say at once, that while there is everyo ducement why we should learn the use of the specutur laryngis, the difficulties are in reality extremely trifint A tolerably steady hand, a moderator lamp, and the necessary mirror, will enable every one of you to loof into the larynx after a very few trials, provided you have suitable subjects to make your first essays upon; and the practice which private or public patients will readio permit of your acquiring will soon make you masters of the whole art.

My own experience further leads me to state that $\vec{\Phi}$ think there must be a difference in the character of German and English patients; for I cannot otherwise account for the complaints which German authors (and there are many who have written on the subject) make with regard to the difficulties that often present them selves in the intolerance of the instrument on the pact of the examinee. Possibly the great susceptibility often spoken of, the irritability of the fauces, the tendency retch, which preclude all laryngoscopic examination fot the time, may result from the examiner being self instructed, and having to find out for himself thosf practical rules which a few explanations from ong already versed in the use of the instrument would have enabled him to lay hold of at once. Still I canner. avoid the conclusion that we have in this respect feweo difficulties to deal with than our German confrères; fot every now and then $I$ have met with cases in which that training of the fauces which they insist upon appears necessary, owing to the reflex action excited by contact of the mirror with the soft parts of the throat. these cases, however, it is not even always, as it appear to me, contact which is necessary to produce the unt pleasant effects; the mere effect of the imagination wilt I am confident, operate so antagonistically to the op rator as to preclude a fair field of inquiry. Strange say, medical men themselves are by no means the bes subjects, either in health or in disease, to deal wit Whether they are naturally more nervous, or, as 
rather think, from their anxiety to assist the speculator, less obedient to his directions, their larynges certainly disclose their secrets less readily than the vocal apparatus of men and women who are unfettered by any anatomical knowledge or diagnostic considerations.

Allow me now briefly to state the main directions which may be given for the guidance of an incipient laryngoscopist.

Place the examinee on a chair of such elevation that, when you sit before him, his head and your own may occupy the same elevation. Place a good moderator or other lamp a little to one side of the patient's occiput, and let him approach as near the table upon which the lamp stands as possible. The patient's head should then be thrown back so as to straighten and stretch the passage to be explored as much as possible, and so that the axis of the introitus laryngis and of the trachea may coincide. As much depends upon the aid afforded by the patient, it is well, as a preliminary to the introduction of an instrument, to calm all apprehension by explaining that no pain can result; and that, if any trifling inconvenience should happen to arise, it will be a signal for the removal of the mirror. Before, however, this is used, it is important to learn how to throw a steady light from the reflector, which is fastened to the forehead by an elastic band, or may be carried between the teeth on a stem. Some beginners find in this proceeding the chief difficulty. Czermak's reflector has, as you see, a central circular spot which is not silvered, and through which the operator is supposed to look. Those who enjoy good eyesight will find the adjustment of their eye to this hole a trouble which they may altogether dispense with, by being content to see with the uncovered eye alone. Having satisfied yourself that you have secured such a position for the lamp, the patient's head, and the reflector, that you obtain the best possible illumination of the patient's mouth, the next step is to prepare the examinee still further for the introduction of the faucial mirror. Let him put out his tongue, and either steady it with the tip of his right forefinger by pressing it slightly against the lower incisors, or take hold of it with the forefinger and thumb of the same hand. The object of this measure is to enlarge the cavity of the mouth, and more particularly to draw forward and flatten the base of the tongue, which otherwise proves an obstruction, and prevents the due passage of the light. The unruliness of the tongue, the obstinate arching of its base, proves a serious difficulty in a few instances, but may be generally overcome by perseverance. Next let the patient be directed to breathe in and out as freely as possible. The very act of a full voluntary inspiration not only expands the fauces, but diminishes the reflex excitability of the parts.

Having made these preparatory arrangements, warm the mirror over the lamp; and, having tested its temperature against your own cheek, to insure its not being unpleasant to the patient, introduce it into his mouth, carefully avoiding all contact with the lips, teeth, or tongue. Push it steadily backwards against the uvula; and, while you rest the third and fourth finger of the hand that holds the mirror against the patient's chin, incline the mirror at such an angle to the horizon (about $75^{\circ}$ ) that the pencil of light which you throw upon it from the reflector may be conveyed into the respiratory tube. The parts that are illuminated will become visible in the mirror; and a little dexterity will soon enable you successively to examine the base of the tongue, the epiglottis and its attachments, the arytenoid cartilages, corpuscula Santorini and the thyro-arytenoid ligaments, the ventricles of the larynx, the vocal cords, and the trachea.

It is scarcely necessary to say that the hand that holds the mirror is to be kept on one side of the patient's mouth, so that it may not come into the line of vision. The stem of the mirror for correct observation will generally come to lie near the bicuspid tooth of the right or left side, according as we employ the right or the left hand. After getting over the first difficulties, it is always well to learn to introduce the mirror with either hand, not only for the purpose of satisfying ourselves that we have seen all accessible parts, but also because the introduction of pencils or probangs into the larynx is facilitated if we can manipulate well with the left hand.

If, after we feel confident in our own ability to use the mirror, there appear to be an undue irritability in the patient's throat, I have found the employment of an astringent gargle of essential advantage in reducing that irritability and allowing a more satisfactory exploration. Matthieu's irrigator has served the same purpose, and may be recommended as an adjuvant in the diagnosis as well as in the therapeutics of laryngeal affections.

The appearance of the living larynx and its appendages conveys a different impression from what most of us would probably anticipate who have only seen it in the dead body, and then only laid open and otherwise altered in its anatomical relations. The epiglottis is occasionally visible without the laryngocope, if the tongue be very forcibly depressed; but this is so rare, that whatever colour it may present at such times cannot be a guide to its normal appearance. When unaffected with any inflammatory congestion, its surface presents a pale yellowish red colour, verging rather to straw-colour than pink. In irritative conditions, we find it in every stage of congestive redness; while on the other hand, in anæmic states, its blanched, bloodless, cream-coloured hue offers a striking contrast with the pink mucous menibranes covering the adjacent parts. As a matter of course, its thickuess varies in proportion to the congestive condition of its mucous investment, the serous effusion that may have taken place, and the character of the inflammation. We see one part more swollen than another, so as to destroy its symmetry, and causing it to appear what vulgarly would be termed lopsided. The epiglottis generally serves as an indication of the pathological condition of adjacent parts; and on this account it is a decided advantage to have obtained a view of this part alone, even if we fail to achieve a deeper view into the laryngeal cavity.

Even if we obtain a good view of the larynx during the first attempts at employing the speculum, it is not quite easy at first sight to recognise the true relative position of the parts. We must bear in mind that we do not see them directly, but through the medium of a mirror; their position is, therefore, reversed. The posterior surface of the epiglottis, that which is turned towards the introitus laryngis, presents itself to the observer as if he were looking through a hole in the cervical part of the vertebral column; the anterior insertion of vocal cords appears to be behind, and vice versâ. The right side of the patient's vocal appendages appears on our left; and similarly the anterior surface of the trachea looks as if it were the dorsal aspect. The uvula, again, gives us a little trouble sometimes, by pertinaciously appearing in front of the mirror and obstructing our view. 'This and other difficulties that we have to combat are not of any magnitude, and will be overcome by a moderate amount of perseverance, and by bearing in mind the anatomical relation of the parts and the simplest laws of optics.

After inspecting the epiglottis, the parts that next attract attention are the prominent parts of the arytenoid cartilages, and more particularly the corpora Santorini. Here we see, in bealth, a pale red smooth mucous membrane; while, in the various laryngeal affections that call for the use of the laryngoscope, we meet with great variations in the hue and state of tumefaetion, generally or unilaterally, of the parts. They are just such as might be anticipated à priori from what we see in other mucous membranes accessible to the eye; 639 
with this proviso, that we have hitherto had no means of localising the morbid conditions, and have been in the habit of setting down a certain class of symptoms as equally indicating affections of the whole laryngeal apparatus. The more $I$ have seen of laryngeal disease, however, by the aid of the laryngoscope, the more I am satisfied that we have been greatly in error in our interpretation of symptoms. The upper thyro-arytenoid ligaments, their colour, their mode of action, and the space which intervenes between them, next call for attention. The amount of mucus investing the different parts is important; and it is well to be on our guard against the deceptive appearances which it presents. An ulcer may be easily simulated by the presence of a patch of viscid mucus; and $I$ bave seen a string of mucus stretched across the laryngeal passage in such a way as closely to resemble a true vocal cord. The expulsive effect of a cough will generally suffice to pnt things in their true light; or it may be necessary to use a camel-hair brush to dislodge a seeming ulcer and expose a healthy or unabraded mucous surface.

The mucous membrane of the upper part of the larynx, and more particularly the ventricies which form the space between the vocal cords and the upper thyro. arytenoid ligaments, present numerous variations, which a little experience in laryngoscopy readily displays. I am inclined to think that these parts play a much more important function in the production of the voice than is ordinarily attributed to them; and that, in the great majority of cases of laryngeal disease accompanied by some modification or impairment of the voice, the morbid condition upon which the hoarseness or aphonia depends does not imply a direct lesion of the cord 2 vocales themselves. I have certainly examined numerous cases of such derangement, in which I could discover no other lesion than that of more or less tumefaction and redness of the mucous membrane in one or all the parts above the vocal cords.

It is possible that, in some of the instances that have fallen under my notice, there may have been a direct impairment of the vibratile power of the vocal cords, or of the controlling influence of the thyro-arytenoid muscles, though not sufficient to be visible by the speculum; but, even without this, we may find an explanation of thr fact by analysing the various elements which are conducive to the production of the human voice.

Any boy who has made a whistle out of a fresh willow or horse-chestnut branch knows how much the sound depends upon the form and size of the air-chamber which he fashions with his pocket-knife behind the slit (or glottis) of his instrument. In the same way, a swelling of the mucous membrane above the vocal cords alters the capacity of the air-chamber in which the laryngeal sound is produced; and this alteration will be effected by a tumefaction of the lateral parts, as also by swelling of the upper and more distant tracts of mucous membrane. I hold it pathologically demonstrated that, although the ventricles and the upper thyro-arytenoid ligaments do not by themselves permit the production of sound, they must both be in a state of integrity to enable the vocal cords to perform their normal functions.

If you look at the diagram representing a section of the vocal apparatus, you will particularly notice the im. portant relation of the ventricles in regard to the air. chamber above the vocal cords. You will observe that, if a swelling of the mucous and submucous tissues occur at this point, the cavity lying immediately above the cordæ vocales must be more or less obliterated. The vocal cords may appear perfectly healthy, and seem to respond readily to the will of the patient; but, if there is not sufficient air immediately above them to take up their vibrations, the effect will be that of a damper in a pianoforte. The case of a gentleman suffering from chronic laryngitis of catarrhal origin, which I have recently examined, and which was accompanied by com- plete aphonia, afforded me a striking corroboration of the correctness of this view. He was unable to produce a sound in the ordinary way-viz., during expiration; which, you will readily convince yourselves, is the ordinary mode of phonation, to use the pet term of laryngoscopists. But he was able, by an inspiratory effort, to produce a laryngeal sound. The mucous membrane of the trachea below the vocal cords being unaffected, the vibrations downwards were effected with sufficient readiness, and met with a sufficient body of air in the tracheal air-chambers, to cause a sound; but, when the air was forced upwards from the lungs, the obliterated ventricles checked the necessary undulations, and no sound resulted.

This I believe to be the explanation of the majority of cases in which the voice is altered, especially in those evanescent forms of hoarseness or aphonia accompanying the ordinary catarrbal affections of the larynx. Need I remind you, in further illustration of the influ. ence upon the voice exerted by parts not in immediate relation with the vocal cords, how even tumefaction of the Schneiderian membrane modifies the voice?

But, if we remember how close the connexion is of the mucous membrane with the various muscles that contribute to phonation, we find a further mode of accounting for modifications of the voice, apparently due to aftections of the membrane at a distance from the $N$ vocal cords, in the impairment of muscular contractile power. This, in its turn, may be propagated through the nerves or the vessels. This readily accounts for arrest of vocalisation where we see nothing but tumefaction in the vicinity of the Santorinian corpuscles; the large bundle of muscular fibres, denominated the arytenoideus muscle, being necessarily more or less involved in any morbid condition of the superim posed mucous membrane, and thus causing a less pero fect adaptation and closure of the vocal cords.

Nor must we lose sight of minuter changes in there. character of the surface, either by injection of bloos vessels, altered epithelium, or vitiated secretion, as in fluencing the pitch and timbre of the voice. These may not necessarily be visible even with the light of the spe. culum ; but it will be scarcely necessary to adduce corroborative illustrations, though the fact may often be brought vividly before the practitioner in the rapid changes which local treatment is able to secure.

Allow me to pass on to the review of some of the cir-? cumstances revealed by the laryngoscope in regard to the vocal cords themselves.

I have already stated one negative fact, which I would repeat for the special benefit of the incipient laryngoscopist: that in many cases of laryngeal disease, where the voice appears even very seriously and permanently to bave suffered, the cords themselves may present their normal appearance. I apprehend that this normalo appearance will take every person by surprise who sees these membranous expansions for the first time in theo living subject. The epiglottis is commonly paler and more glistening than the surrounding parts; but the $N$ contrast offered by the vocal cords with the adjacent mucous membrane is still more striking. They areo almost white, of a pale cream colour, with a pearly sheen, quite different from the velvety character of ordi- $N$ nary mucous membrane. This peculiar colour enables? us readily to recognise them, provided the light is pro-c perly thrown into the larynx, and minute changes areo readily recognised in and about them. This part of the organs of phonation is one of the most interesting sub-a jects for examination, both physiologically and patholo- $\mathbb{E}$ gically; and the study of their movements alone is? amply sufficient to repay you for any little trouble, and it really is but a little trouble, that the acquisition of the necessary dexterity may involve. To those of you who would wish to go more fully into the physiological par-o of the question, I would strongly recommend a perusal $\stackrel{\Phi}{\circ}$ 
of M. Bataille's recent work on Phonation, written by a gentleman who, though by profession a teacher of singing, was educated to medicine, and distinguished himself in the earlier part of his career as an anatomist.

Although, as I have said, the vocal cords do not always exhibit pathological changes when, $\grave{a}$ priori, we might have anticipated them, they nevertheless present various lesions which could never have been discrimi. nated without the speculum. We see in them (and I speak here, as throughout, from actual observation) the different degrees of inflammation, from the faintest injection to diffused redness, ulceration and loss of sub. stance of greater or less extent, new growths, and evidences of pralysis, for none of which we have hitherto possessed any satisfactory and certain indication in the symptoms accompanying these conditions. Even my limited knowledge of the laryngoscope has satisfied me that we have been in the habit of confounding conditions widely distinct and necessarily demanding totally dif. ferent treatment. I have seen warty excrescences simulate a nervous affection; I have seen paralysis with the symptoms of inflammation; I have seen urgent symptoms of acute laryngitis without a trace of inflammation. Imagine a case of the last kind coming to you suffering under extreme dyspnœa and aphonia, and telling you that, on a former occasion, the inflammation had been so severe as to necessitate tracheotomy; contemplate the effects that your venesection and leeches, calomel and tartar emetic, would produce; and say whether it is not our duty to familiarise ourselves with the use of an instrument which tells us that our diagnosis, and conse. quently our treatment, was utterly wrong?

Almost the first case in which I employed the laryngoscope was one which very forcibly impressed upon me the practical advantages derivable from the instrument. A man was under my care with cough, pain under the right clavicle, circumseribed dulness at that spot, a blowing systolic murmur, ibidem, a pulse feebler in the right than in the left radial, and, as it were to corroborate the diagnosis compelled by the foregoing symptoms, aphonia. Who, under such circumstances, would have failed to diagnose a subclavian aneurism, causing, by its pressure on the recurrent, a paralytic condition of the thyroarytenoid muscles? What did the laryngoscope demonstrate? Two large epithelial growths proceeding from the anterior junction of the vocal cords. This did not necessarily vitiate the previous diagnosis, though it presented an unexpected feature, compelling a revision of the entire case, and a very evident indication for treatment at least in one direction not previously manifest.

The literature of laryngoscopy already furnishes us with numerous instances of growths occupying the vocal cords and their vicinity; and, with an improved diagnosis, we already see an advance in the more precise therapeutics of laryngeal affections. I have long satisfied myself of the perfect possibility of applying remedial agents to the interior of the larynx with certainty, and with benefit to the patient, by the means of sponges; but, before the laryngoscope came into use, we were necessarily in the dark both as to the nature and locality of the morbid condition we had to deal with. Our applications were made at a venture. Sometimes they succeeded, but they as frequently failed; because a general mopping out of the laryngeal cavity in a disease affecting only a given point was as likely to do harm as good, and because it was the merest guesswork as to what remedy was requisite.

The speculum laryngis enables us first to see defi nitely the characters of the malady calling for our remedial measures; and, secondly, to direct the application of sponges, camel-hair brushes, wire loops, caustics, inhalations, or irrigations, with something like an approach to the certainty of the issue which we can calculate upon in other maladies amenable to physical methods of diagnosis.

Few of us, who have watched the effects of galvanism, can fail to arrive at the conclusion that it is a very valuable agent in the treatment of disease. Its influence on the nerrous, and I think even more upon the muscular, system, in cases suitable to its application, is undeniable. It is one among the various agents upon which we have been in the habit of ringing the changes in laryngeal disease. But of what good can it be in a case dependent upon syphilitic ulcer of the vocal cords, upon catarrhal inflammation of the laryngeal mucous membrane; or in epithelial tumour growing from some part of the organs of phonation?

A simple uncomplicated case of paralysis of the vocal cords may be now diagnosed with as much certainty as a paralytic condition of any external part. We can see with the speculum that there is a want of symmetry of the movements of the two sides of the larynx, or that the movements are generally feeble or arrested; and we then apply our moist sponges, and direct the galvanic current with the precision, and with the same reasonable hope of success, with which we are able to direct it through the muscle of an extremity paralysed by rheumatism or by lead-poison, or irregularly excited by choreic spasm. Other modes of treatment are also of great value in such cases, and will readily suggest themselves. I place before you an illustrative diagram of a paralytic affection of the right vocal cord, which had caused aphonia for seven months. The patient was under treatment for a fortnight without benefit, until, the laryngoscope having revealed the true condition of the parts, I caused her to use Matthieu's irrigator charged with a solution of tannic acid; and, after two sittings, she had recovered her voice, and the parallelism of the vocal cords was shown by the laryngoscope to have been restored.

If you refer to the literature of the subject, you will find that there is also evidence of the utility of the laryngoscope in exploring the condition of the inferior surface of the vocal cords. This, of course, can only be done in rare cases of chronic disease necessitating tracheotomy. The tracheal opening is used for the purpose of introducing a mirror, which, being turned upwards and receiving the light of the reflector, gives an image of the under side of the vocal cords with the same precision as the more ordinary mode of employing the laryngoscope affords of the upper parts. Of this I know nothing from direct observation; but $I$ mention it because it may afford a clue to those cases in which we can detect no organic changes in the vocal apparatus, or in which only the tracheal mucous membrane appears to be the seat of any lesion.

The affections of the trachea are to a certain extent well brought out by the laryngoscope. If the larynx is fully open, there is no difficulty in throwing a good light on the anterior surface of this channel; the rings and the intervening spaces are readily recognisable under these circumstances; and their changes in colour or organisation cannot fail to be discovered. Variations of redness are most frequently met with. But, in illustration of the remark made just now of the influence exerted upon vocalisation by the parts below the vocal cords, I may state that, in one case of long standing aphonia connected or complicated with incipient pulmonary tubercle, I saw the trachea studded with small round yellowish spots, which I regarded as miliary granulations or ulcers. No other abnormity of the vocal apparatus could be discovered; and the vocal cords themselves appeared to act uniformly and sym. metrically.

You will find it stated that the laryngoscope enables you to see down to the bifurcation of the trachea. I $\mathrm{am}$ confident that $I$ have in one case succeeded in seeing the orifices of the bronchi; but this is almost an accidental 
circumstance, which cannot be reckoned upon. Whether, in the case of foreign bodies being introduced into the trachea, we can discover them, must depend mainly upon the greater or less readiness with which the patient bears the examination. I have not met with a case in books or in practice where I was able to test the laryn. goscope under such circumstances. I should, however, deem it perfectly feasible, seeing how little reflex irrita. bility is often found to exist after the foreign body has passed the chink of the glottis.

As to the question of the treatment of laryngeal affections, I do not propose now to go into it more fully. I have merely adverted to it in so far as it served to illustrate the use of the laryngoscope. For my own part, I am assured that both for laryngeal disease, and negatively or indirectly for the affections of other organs, this method of exploration is of extreme value. It is only necessary to make a few laryngoscopic examinations of suspected laryngeal disease to satisfy ourselves that without it our diagnoses not only want precision, but are destitute of any reliable basis. But this morning (Nov. 19th) a patient was brought to me with hoarseness of three years duration, depending upon a pathological condition which it would have been simply impossible to have surmised, but which the laryngoscope made as plain as if the parts had been displayed by dissection. The epiglottis was contracted so as to form a narrow triangular opening. The mucous membrane investing it and the vicinity was reddened and congested. The contraction, from reasons which it is unnecessary to enter into here, was probably congenital; and the hoarseness was attributable to a comparatively trifling affection of the mucous membrane, though obstinate on account partly of the patient's mode of living, partly, and yet more, owing to the peculiar malformation alluded to. I need scarcely point out how essentially the correctness of our diagnosis and prognosis is advanced in such cases by this new method of examination.

It is a field in which there are as yet but few la. bourers, but it is one which I would earnestly invite you to cultivate. I may repeat, that the pleasure you will derive from acquiring the necessary facility of manipulation far outweighs the labour you may have to bestow. Physiologically and pathologically, and, $\dot{a}$ fortiori, therapeutically, the laryngoscope is a great acquisition, which we should all utilise. As one man uses the stethoscope with greater facility and precision than another, so one practitioner may become a more ready laryngoscopist than another; but, in the same sense as the former in. strument has become the common property of the pro. fession, so ought the latter to be understood by all. This, indeed, is the gist of my observations; and, although I am fully aware of the imperfect character of these jottings, I should consider that they were not fruitless if I had succeeded in convincing those of you who have not yet familiarised themselves with the laryngoscope, that it is an acquisition of considerable value in scientific medicine, deserving of your attention.

\section{NOTE ON A DISEASE OF THE EYELID OF} AS'THENIC ERYSIPELATOUS TYPE,

OCCURRING IN YOUNG FEMALE CHILDREN; AND ON COLLODION AS AN EXTERNAL APPIICATION.

By J.V. Solomon, F.R.C.S., Surgeon to the Birmingham aud Midland Eye Hospital.

THE following group of symptoms is sufficiently rare in the Midland Counties, and, from its resemblance to ophthalmitis, alarming enough, when not understood, to deserve a special notice.

A girl, under eight years of age, more often under four, whose general health has been latterly falling off, presents an enormous swelling of one of the upper eyelids, which is shiny and red. The swelling extends over the whole lid, and forms an arch which rests on the brow and tarsal border. The lower palpebra, of healthy

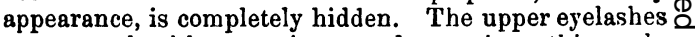
are matted with secretion; and a copious thin, pale,, . yellow discharge flows from the eye.

Medical advice is generally sought in three or fouro⿱ days; when, on raising the lid with a wire speculum, the conjunctiva, instead of being, as in purulent ophthalmia, of a bright red colour, highly tumid, villous, or granular, is found to be flat and of a pale pink or dirty red shade. $\frac{S}{J}$ In exceptional cases it is eroded in spots, and covered $\mathbb{\Phi}$ by a thin film of yellowish lymph. The conjunctiva of the globe is very slightly, if at all, injected.

With one exception, the cornea has been always per- $\vec{O}$ fectly transparent in the cases which $I$ have seen, and. so remained. In the instance referred to, superficial $\overrightarrow{\mid}$ ulceration and vascularisation appeared on the margin of the membrane after the complete subsidence of the primary local disease. In no case has leucorrhœa been 3 present.

The period of the year at which the disease has occurred has been the fourth quarter. I do not remember to have seen more than two cases in one year; sometimes; not one.

The plan of treatment, which has never disappointed me, and under which the disease rapidly subsides, consists in the application of collodion to the integu- N ment of the swollen lid; injections of nitrate of silver to the conjunctiva, of the strength of one grain of the salt to an ounce of distilled water; the internal administration of quinine (a mild aperient having been pre- $\frac{\mathbb{D}}{3}$ mised, if necessary); with a bland and nutritious diet. The importance of general hygienic measures receiving@ at the same time a practical recognition.

At one time I used to get rid of the tumefaction $b, \vec{\infty}$ the application of a small blister to the temple. Collodinn is, however, preferable; not only on account of its beigi painless and more safe, but because its curative effecto is more rapid.

I also apply collodion in cases of infantile purulent ophthalmia, when attended with redness and consider-0 able infiltration of the superior palpebra; by exert- $\frac{0}{\Phi}$ ing an even and firm compression, and astringing the vessels, it causes rapid absorption of the intercellular exudation.

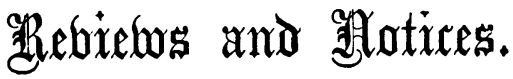

Lectures on the Distinctive Characters, Pa thology, and Treatinent of Continued Fevers delivered at the Royal College of Physicians of London. By Alexander Tweedie, M.D., F.R.S. Fellow of the Royal College of Physicians of Lon? don; Consulting Physician to the London Feve@ Hospital, etc. Pp.301. London : 1862.

a Treatise on the Continued Fevers of Great Britain. By Charles Murchison, M.D., Fellow of the Royal College of Physicians; Senior Phy sician to the London Fever Hospital, etc. Pp. 63\% London : 1862.

THE revolution which has taken place during thes last quarter of a century in the views of physicians as to the nomenclature and pathology of the cons tinued fevers is an ample justification for the apo pearance of such treatises as those before us; and prima facie they have the greater claim to be wecomed by the profession, inasmuch as they are both written by men who have had much experience i⿱ their subject. Of the authors, one, Dr. Murchrson 